DOI: $12737 / 25198$

УДК $630 * 8$

АНАЛИЗ ПРОСТРАНСТВЕННОГО РАЗМЕЩЕНИЯ ЛЕКАРСТВЕННЫХ РАСТЕНИЙ С ПРИМЕНЕНИЕМ ГИС-ТЕХНОЛОГИЙ НА ПРИМЕРЕ ЛИСИНСКОГО УОЛХ

кандидат сельскохозяйственных наук, доцент А. А. Никифоров ${ }^{1}$ кандидат технических наук, доцент А. И. Никифорова ${ }^{1}$

1 - ФГБОУ ВО «Санкт-Петербургский государственный лесотехнический университет имени С.М. Кирова», г. Санкт-Петербург, Российская Федерация

Заготовка лекарственно-растительного сырья является одним из перспективных направлений для российских производителей, рынок которого характеризуется как развивающийся. Исследования по пространственному анализу и определению биологическогозапаса лекарственно-растительного сырья выполнены на примере Лисинского учебноопытного лесхоза. На территории лесхоза распространены и имеют потенциальное промысловое значение следующие лекарственные растения: ландыш (Convallária majalis L.), зверобой (Hypéricum perforátum L.), валериана (Valeriána officinális L.), кислица (Óxalis acetosella L.), багульник (Ledum palustre L.), крапива двудомная (Urtíca dióica L.). Сведения о запасах и территориальном размещении лекарственных растений были получены с применением геоинформационных технологий. Биологический запас лекарственного сырья определен по региональным таблицам для средней многолетней урожайности с учетом типов условий произрастания, типов леса и таксационной характеристики насаждений. Если учитывать максимальную урожайность одного конкретного типа леса можно сказать, что наибольшую массу имеет багульник и крапива. В результате определено, что заготовка лекарственных растений на территории лесхоза возможна по всем рассматриваемым видам лекарственных растений, что позволит расширить объемы заготавливаемого ценного сырья. Информация о запасах и размещению лекарственных растений позволит оптимизировать работы по выбору маршругов заготовки приоритетных видов сырья. С помощью ГИС-технологий был определен суммарный биологический запас рассматриваемых видов лекарственных растений для Лисинского УОЛХ. Пространственный анализ позволил определить районы с максимальной урожайностью лекарственных растений. Географические информационные системы могуг применяться в качестве инструмента для мониторинга, инвентаризации, охраны и организации промышленной заготовки лекарственного сырья. Разработанные технологии могуг быть использованы для определения урожайности грибов и дикорастущих ягод.

Ключевые слова:геоинформационные системы, лесные ресурсы, лекарственное сырье, лекарственные растения, пространственный анализ.

\title{
ANALYSIS OF SPATIAL DISTRIBUTION OF MEDICINAL PLANTS USING GIS-TECHNOLOGIES ON THE EXAMPLE OF LISINSKY SCIENTIFIC-EXPERIMENTAL FORESTRY
}

$\mathrm{PhD}$ in Agriculture, Associate Professor A. A. Nikiforov ${ }^{1}$

$\mathrm{PhD}$ in Engineering, Associate Professor A. I. Nikiforova ${ }^{1}$

1 - Federal State Budget Education Institution of Higher Education «Saint-Petersburg State Forest Technical University under name of S.M Kirov», Saint-Petersburg, Russian Federation

\begin{abstract}
Harvesting of medicinal-plant raw materials is one of the most promising areas for Russian producers, the market of which is characterized as developing one. Research on spatial analysis and definition of biological stock of medicinal-plant raw materials is made on the example of Lisinsky scientific-experimental forestry. The following medicinal plants: lily of the valley (Convallária majalis L.), St. John's wort (Hypéricum perforátum L.), valerian (Valeriána officinális L.), wood sorrel (Óxalis acetosella L.), Labrador tea (Ledum palustre L.), stinging nettle (Urtíca dióica L.) are widespread on the territory of the forestry and have potential commercial value. Data on stocks and territorial location of the medicinal plants were obtained with the use of geoinformation technologies. Biological stocks of medicinal raw materials is defined by the regional table for average long-term
\end{abstract}




\section{Природопользование}

yield based on the types of growing conditions, forest types and taxonomic characteristics of plants. If we consider the maximum yield of one specific type of forest, we can say that Labrador tea and stinging nettle has the greatest mass. In the result, it was determined that harvesting of medicinal plants in the territory of forestry is possible for all the considered types of medicinal plants, which will increase the volumes of harvesting and storage of valuable raw materials. Inventory information and location of medicinal plants will enable to optimize the choice of the routes for the priority procurement of raw materials. Using GIS technology the total biological stock of the types of medicinal plants in Lisinsky scientific-experimental forestry was determined. Spatial analysis allowed determining the areas with the highest yield of medicinal plants. Geographic information systems can be used as a tool for monitoring, inventory, protection and organization of the industrial harvesting of medicinal raw materials. The developed technology can be used to determine the yield of mushrooms and wild berries.

Keywords: geographic information systems, forest resources, medicinal raw materials, medicinal plants, spatial analysis.

Благодаря тому, что геоинформационные технологии позволяют эффективно решать вопросы по анализу и моделированию географических объектов, наблюдается увеличение интереса к ним в сфере планирования заготовки лекарственно-растительного сырья. Для комплексной оценки популяций дикорастущих лекарственных растений, имеющих приуроченность к определенным ландшафтам используетсягеопространственный анализ, позволяющий обобщить такие сведения как флористический состав лекарственных растений и определить места, подходящие для заготовки лекарственных растений, имеющих наибольшее распространение и значения с точки зрения фармакологических предприятий.

Заготовка лекарственно-растительного сырья является одним из перспективных направлений для российских производителей, рынок которого характеризуется как развивающийся. Это связано с положительной динамикой потребления лекарственных трав и сборов, так как препараты, изготавливаемые из лекарственного растительного сырья обладают относительной безопасностью действия (в отличии от медицинских препаратов, имеющих большое количество противопоказаний), возможностью рационального сочетания лекарственных растений между собой и синтетическими лекарственными препаратами, а также имеют ценовую доступность.

Заготовка лекарственного сырья во многом зависит от четкой организации заготовительного процесса. То есть с точки зрения практиков, которые и занимаются в дальнейшем сбытом получаемого сырья, за основной показатель принимают распределение лекарственного сырья по территории. Основной единицей учета площади распространения лекарственных расте- ний при этом выступают территории с одинаковыми лесотаксационными показателями. Учету подлежат участки с наличием лекарственных видов, подлежащих промысловой заготовке.

Объекты и методика исследований.

Исследования по пространственному анализу и определению биологической урожайности лекарственно-растительного сырья выполнены на примере Лисинского учебно-опытного лесхоза (Лисинского УОЛХ). Учебно-опытный лесхоз располагается в Ленинградской области в центральной части Тосненского административного района. Территория лесхоза представляет собой компактный лесной массив, протяженность с севера на юг составляет 34 км, с запада на восток - 18 км. По материалам лесоустройства, которое проводилось в 2005 г., общая площадь составляет 28384 га. На территории лесхоза распространены и имеют потенциальное промысловое значение следующие лекарственные растения: ландыш (Convallária majalis L.), зверобой (Hypéricum perforátum L.), валериана (Valeriána officinális L.), кислица (Óxalis acetosella L.), багульник (Ledum palustre L.), крапива двудомная (Urtíca dióica $L$.).

Пространственный анализ лекарственных растений выполнялся с применением геоинформационной системы Лисинского учебно-опытного лесхоза [10]. Разработанная система зарегистрирована в Федеральном институге промышленной собственности, получено свидетельство о регистрации программы для ЭВМ номер 2012614272 от 14.05 .2012 г. «Геоинформационная система Лисинского учебно-опытного лесхоза филиала федерального бюджетного образовательного учреждения высшего профессионального образования "Санкт-Петербургский государственный лесотехниче- 


\section{Природопользование}

ский университет имени С.М. Кирова"», авторами программы являются: Никифоров А.А., Алексеев А.С. Программа реализована в среде MapInfo. При создании ГИС в качестве картографической основы использовались планы лесонасаждений, а в качестве тематической БД - таксационные описания $[1,2,11,12]$.

В ГИС были подготовлены таблицы по группам лесотаксационных показателей, для этого применялся структурированный язык запросов SQL [3, 4, 5, 13]. С помощью языка SQL реализованы запросы как к тематической, так и к пространственной информации.

Результаты и их обсуждение.

Биологический запас лекарственного сырья определен по региональным таблицам для средней многолетней урожайности с учетом типов условий произрастания, типов леса и таксационной характеристики насаждений [7, 8, 9]. На основе средних показателей урожайности лекарственных растений были получены тематические карты [6] с распределением территории лесхоза на участки, пригодные для заготовки лекарственного сырья. В первом случае карты показывают общее размещение лекарственных растений в зависимости от преобладающей породы и типа леса (рис. 1). Здесь можно увидеть, что за исключением багульника, лекарственные растения произрастают равномерно по всей территории лесничества, отличие заключается в количественном показателе урожая растений. Поэтому было принято решение показать размещение лекарственных растений с максимальной урожайностью на единице площади (рис. 2). Это наглядно показывает участки территории лесничества, наиболее характерные для произрастания определенного вида растений и позволяет сориентироваться по местности в связи с организацией работ по заготовке необходимого вида лекарственного сырья.

Зная урожайность лекарственных растений в различных типах лесорастительных условий и типах леса на единице площади (кг/га) и площадь участка (выдела), для которого ведутся расчеты, была получена величина биологического запаса лекарственных растений на этой территории (табл.).

По результатам таблицы были построены диаграммы. Биологический запас ландыша в смешанных насаждениях кисличного типа леса (C2-С3) составляет 65508 кг, или 95,6 \% (рис. 3, б). Участки с данным типом леса расположены равномерно по всей территории лесхоза (рис. 2, д).

Зверобой произрастает в низкополнотных (полнота 0,4 и ниже) смешанных насаждениях и его биологический запас составляет 37530 кг, или $60,8 \%$ (рис. 3 , б). На нелесных площадях отведенных под сенокос запас зверобоя составляет 23104 кг (37,4 \%). Сенокосы обладают максимальной урожайностью сырьевой фитомассы на единицу площади. Пространственное размещение сенокосов преимущественно сконцентрировано в центральной части учебно-опытного лесхоза (рис. 2, б).

Валериана произрастает на переувлажненных землях долгомошного типа леса, ее биологический запас составляет 37311 кг (72\%) и приходится на смешанные насаждения. Участки, где произрастает валериана, расположены равномерно по всей территории лесхоза (рис. 2, в).

Багульник встречается на верховых болотах, а также в сосняке долгомошном и еловолиственных насаждениях (рис. 1, г). Общий урожай багульника составляет 355469 кг. На верховых болотах багульник обладает максимальной урожайностью и с данных участков можно получить 203725 кг багульника. Местоположение участков преимущественно в южной части Лисинского УОЛХ (рис. 2, г).

Крапива двудомная произрастает в смешанных насаждениях, максимальная урожайность наблюдается в травяно-таволговом типе леса.

Кислица на территории Лисинского УОЛХ встречается преимущественно в смешанных насаждениях кисличного, брусничного, и черничного типов лесов (С2-С3) и незначительно в сосняках и ельниках кисличниках. Урожай кислицы в смешанных насаждениях составляет 243969 кг (85,7 \%) (рис. 3, б), расположены в центральной и северной части лесхоза (рис. 2, д).

Если учитывать максимальный биологический запас одного конкретного вида растений (рис. 4) можно сказать, что наибольшую массу имеет багульник, а затем крапива и ландыш.

\section{Заключение}

По материалам тематической и пространственной баз данных в Лисинском учебно-опытном лесхозе определены площади для основных видов лекарственных растений и выполнен анализ пространственного 

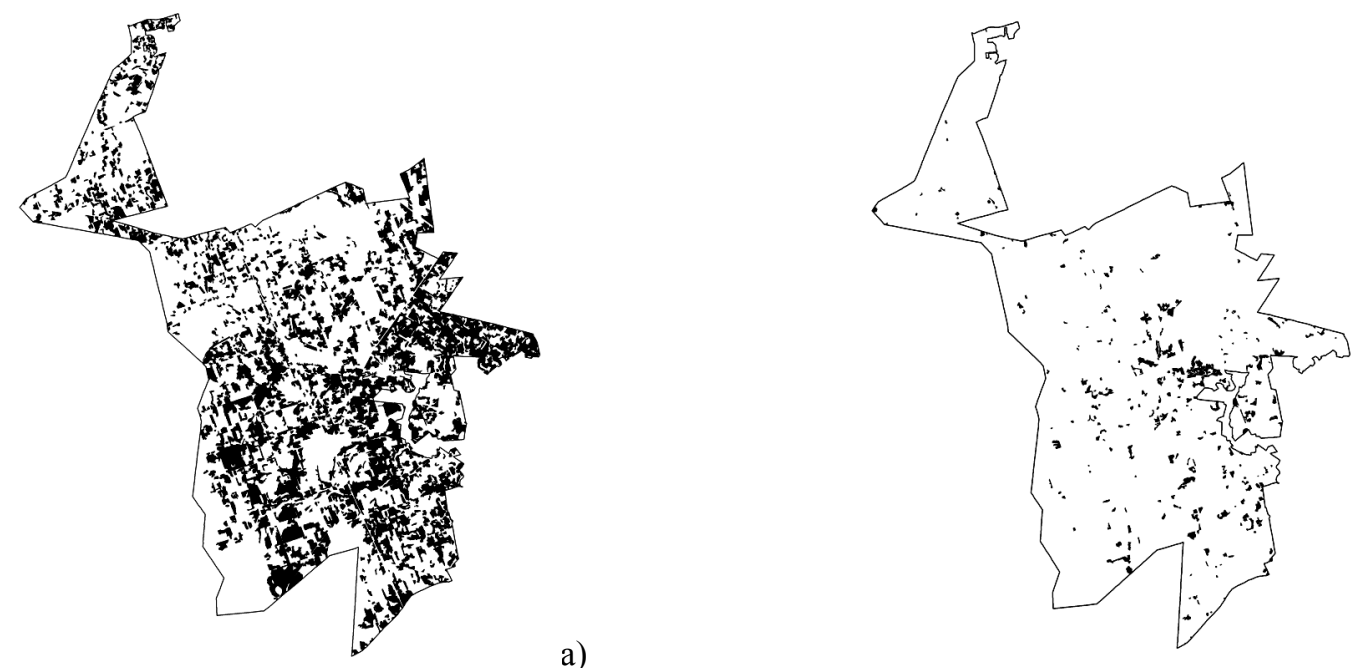

a)

б)
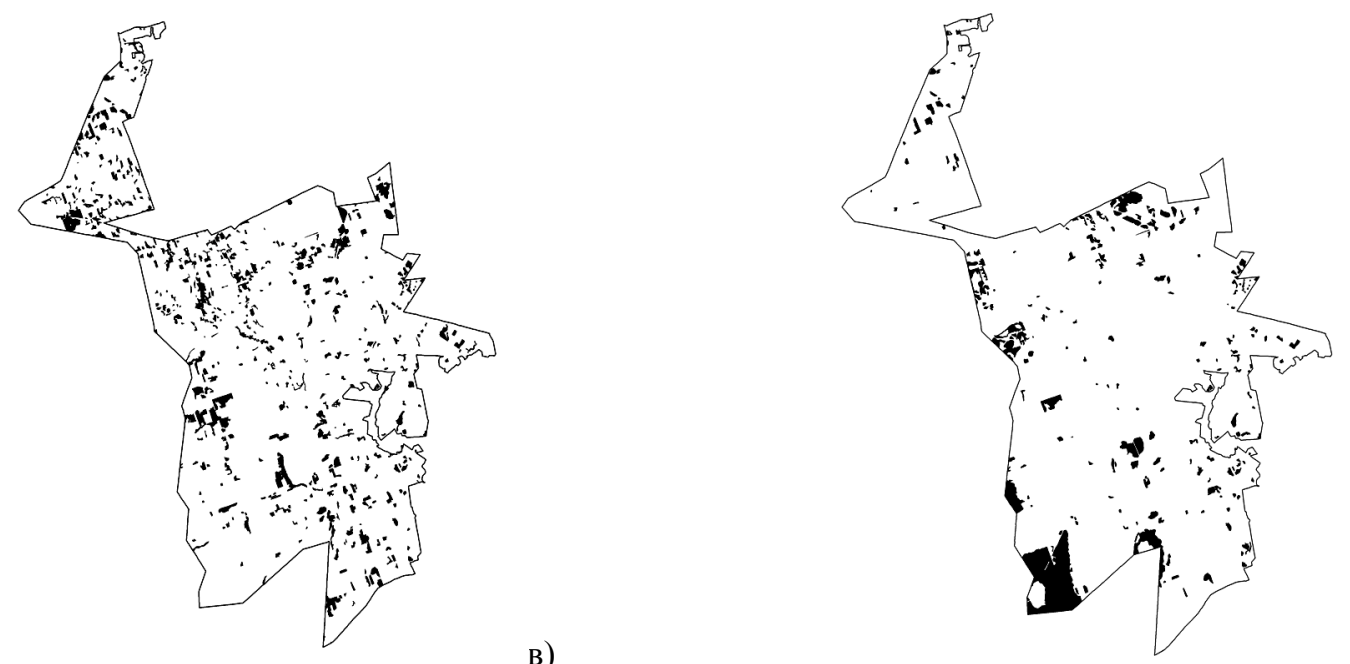

г)
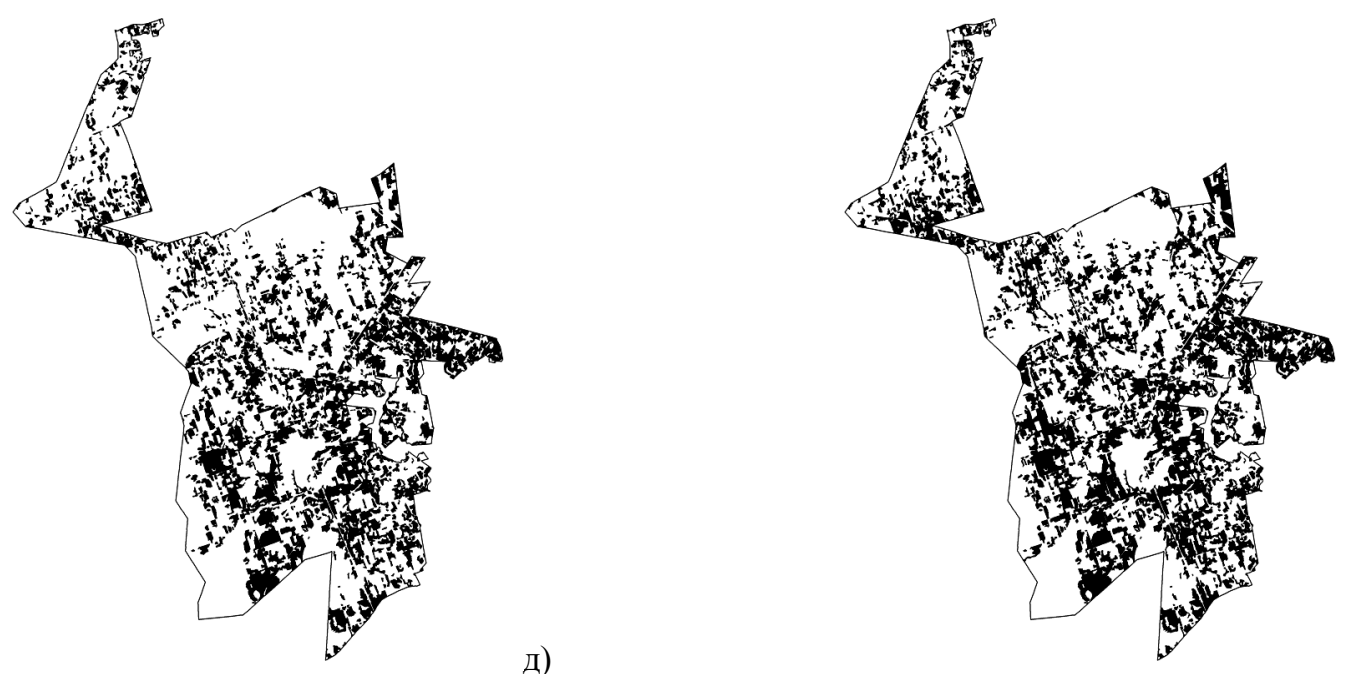

Рис. 1. Пространственное размещение лекарственных растений

e)

а) - кислица, б) - зверобой, в) - валериана, г) - багульник, д) - ландыш,

е) - крапива 

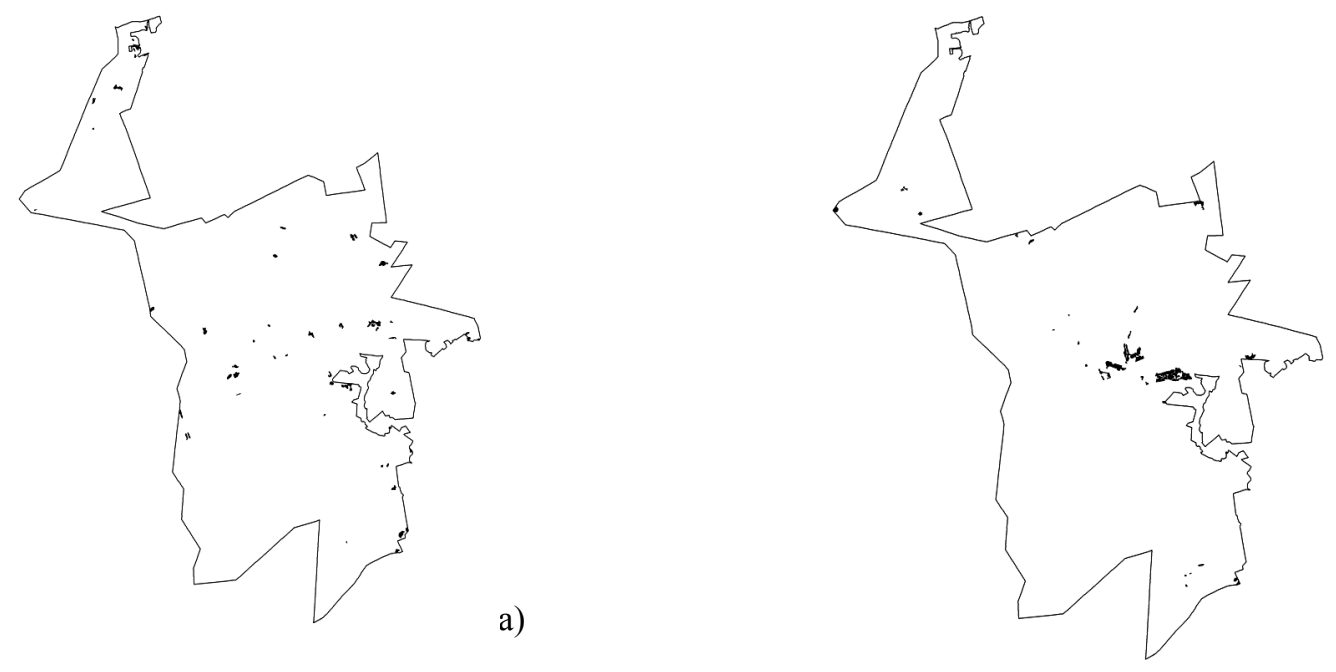

б)
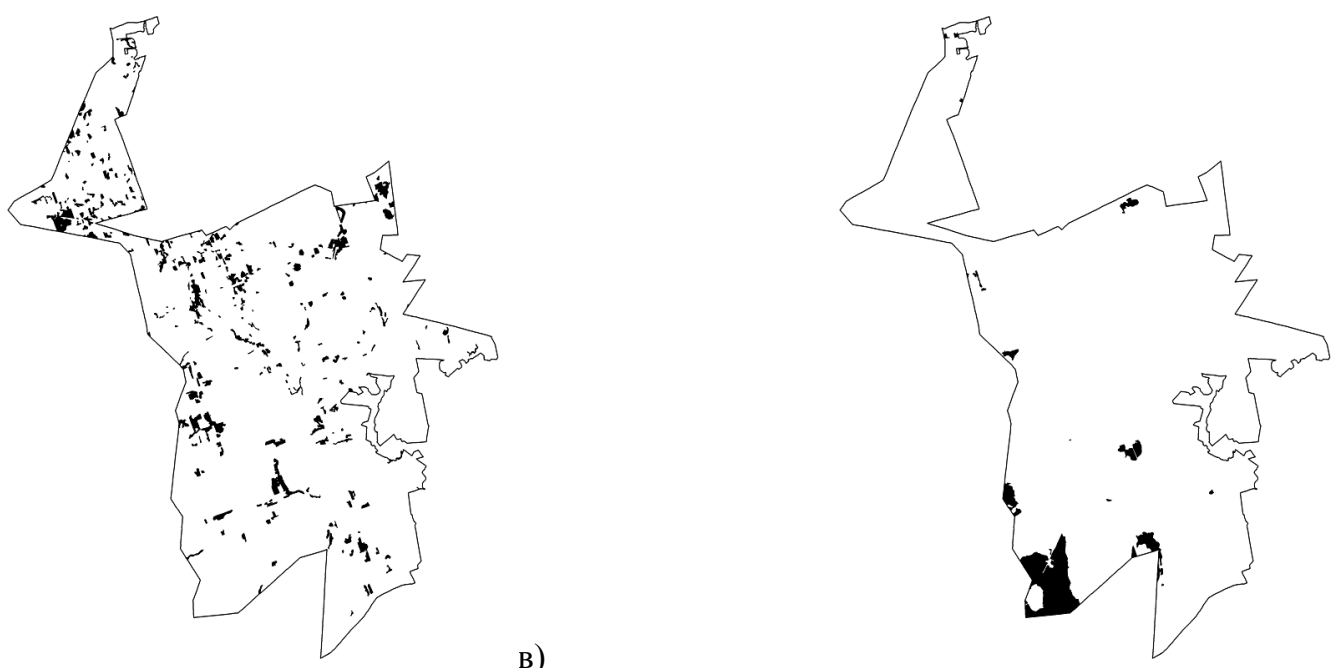

г)
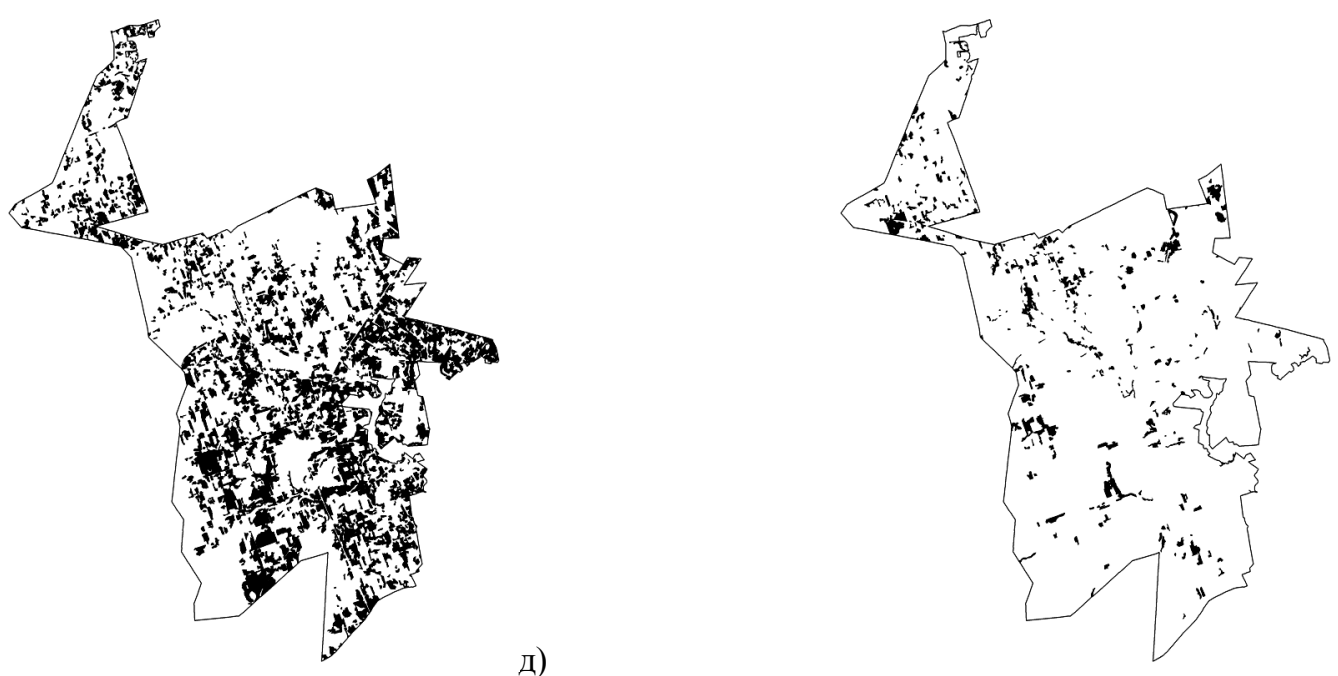

e)

Рис. 2. Пространственное размещение лекарственных растений с максимальной урожайностью а) - кислица, б) - зверобой, в) - валериана, г) - багульник, д) - ландыш, е) - крапива 


\section{Природопользование}

Таблица

Биологический запас лекарственных растений в различных типах леса

\begin{tabular}{|c|c|c|c|c|c|c|c|c|c|}
\hline \multirow[b]{2}{*}{ Насаждения } & \multirow[b]{2}{*}{ Тип леса } & \multirow[b]{2}{*}{ ТУМ } & \multirow{2}{*}{$\begin{array}{c}\text { Пло-щадь, } \\
\text { га }\end{array}$} & \multicolumn{6}{|c|}{ Биологический запас, кг } \\
\hline & & & & Ландыш & Зверобой & Вале-риана & Багульник & Кислица & $\begin{array}{c}\text { Крапива } \\
\text { двудомная }\end{array}$ \\
\hline \multirow{4}{*}{ Сосновые } & $K C$ & $B 2$ & 119,4 & 0 & 0 & 0 & 0 & 15044,4 & 1194 \\
\hline & $4 B, Y B O$ & $A 3$ & 276,2 & 0 & 0 & 0 & 0 & 4143 & 0 \\
\hline & ДЛ & $A 4$ & 330,1 & 0 & 0 & 4951,5 & 46214 & 0 & 0 \\
\hline & БГ,CФ & $A 5$ & 444,6 & 0 & 0 & 0 & 88920 & 0 & 0 \\
\hline $\begin{array}{c}\text { Сосново- } \\
\text { лиственные }\end{array}$ & $K C$ & $B 2$ & 74,9 & 449,4 & 0 & 0 & 0 & 0 & 0 \\
\hline Еловые & $K C$ & $C 2$ & 239,9 & 0 & 0 & 0 & 0 & 16793 & 0 \\
\hline \multirow{2}{*}{ Елово-лиственные } & ЧВ,ДЛО & B3 & 357,8 & 2504,6 & 0 & 6082,6 & 0 & 0 & 28624 \\
\hline & ДЛ & $B 4$ & 151 & 0 & 0 & 3322 & 16610 & 4228 & 0 \\
\hline $\begin{array}{c}\text { Елово-лиственные } \\
\text { с полнотой } 0,4 \text { и } \\
\text { ниже } \\
\end{array}$ & ЧВ,ДЛО & B3 & 44,6 & 0 & 490,6 & 0 & 0 & 0 & 0 \\
\hline \multirow[t]{2}{*}{ Смешанные } & $\begin{array}{c}K C, \overline{, E}, \\
Ч B\end{array}$ & $C 2-C 3$ & 8132,3 & 65058,4 & 0 & 0 & 0 & 243969 & 813230 \\
\hline & ДЛ,TТ & $C 4$ & 1243,7 & 0 & 0 & 37311 & 0 & 0 & 174118 \\
\hline $\begin{array}{c}\text { Смешанные с } \\
\text { полнотой } 0,4 \text { и } \\
\text { ниже }\end{array}$ & $\begin{array}{c}K C, Б P, \\
Ч B\end{array}$ & $C 2-C 3$ & 834 & 0 & 37530 & 0 & 0 & 0 & 0 \\
\hline \multirow[b]{2}{*}{ Березовые } & $T A B, K C$ & $B 2-B 3$ & 7,2 & 50,4 & 0 & 0 & 0 & 417,6 & 864 \\
\hline & $\begin{array}{c}T P C \Phi \\
O C \Phi\end{array}$ & B5 & 0,4 & 0 & 0 & 0 & 0 & 0 & 34 \\
\hline $\begin{array}{c}\text { Березовые } \\
\text { с полнотой } 0,4 \text { и } \\
\text { ниже } \\
\end{array}$ & $T A B, K C$ & $B 2-B 3$ & 6,2 & 0 & 310 & 0 & 0 & 0 & 0 \\
\hline \multicolumn{3}{|c|}{ Вырубка } & 7,9 & 0 & 316 & 0 & 0 & 0 & 0 \\
\hline \multicolumn{3}{|c|}{ Сенокос } & 144,4 & 0 & 23104 & 0 & 0 & 0 & 0 \\
\hline \multicolumn{3}{|c|}{ Верховое болото } & 814,9 & 0 & 0 & 0 & 203725 & 0 & 0 \\
\hline
\end{tabular}

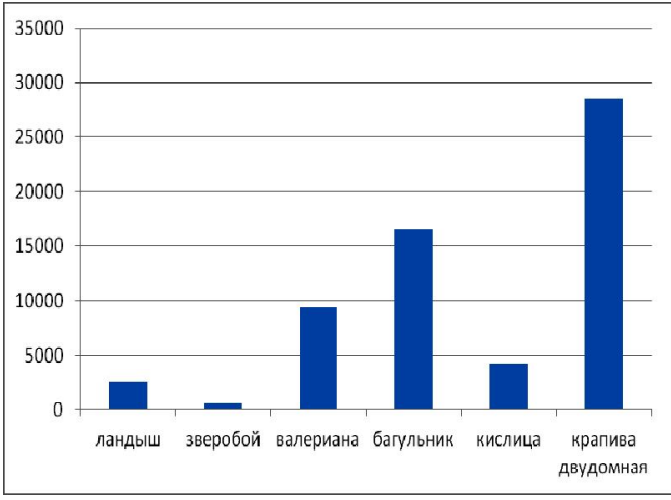

a)

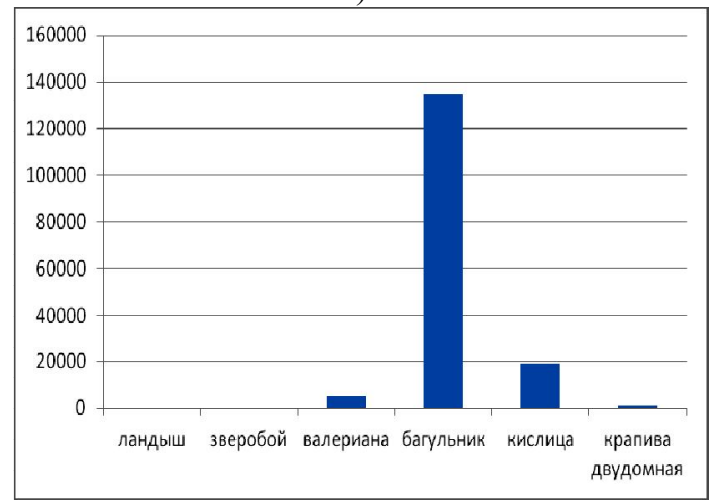

в)

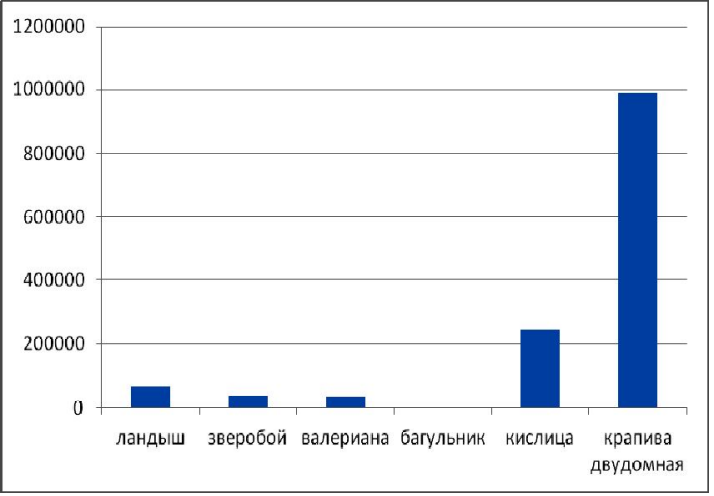

б)

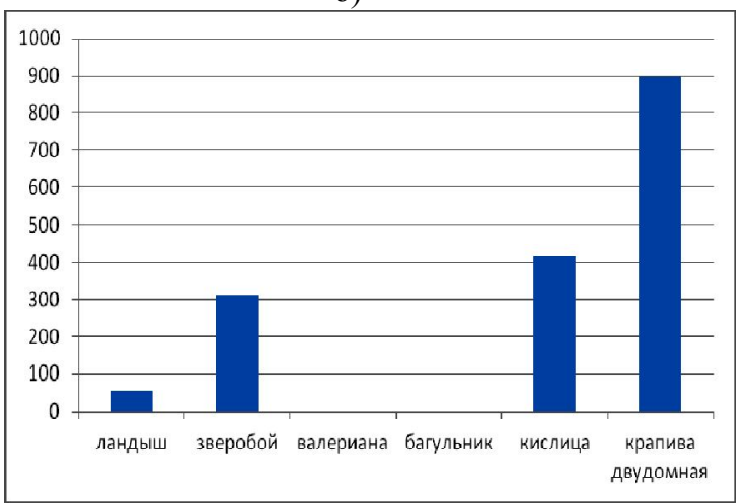

г)

Рис. 3. Биологический запас лекарственных растений в насаждениях, кг:

а) - елово-лиственных, б) - смешанных, в) - с преобладанием сосны, г) - с преобладанием березы 


\section{Природопользование}

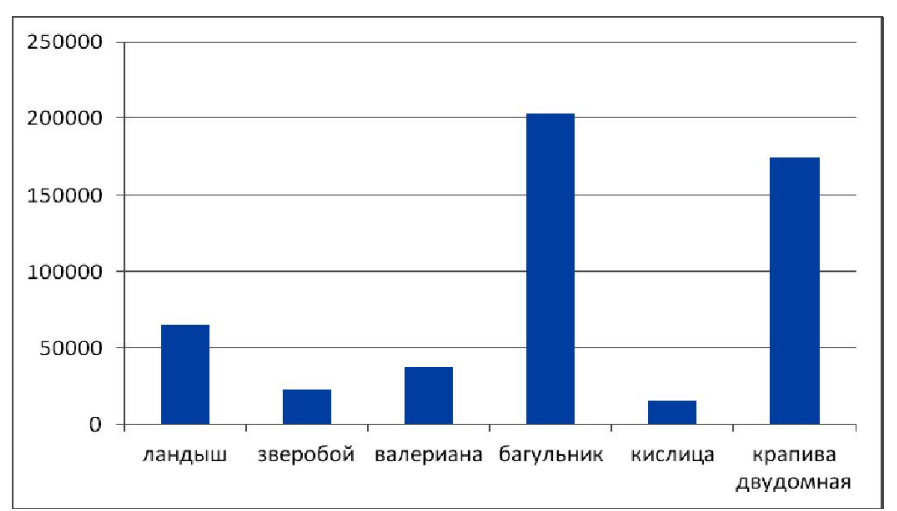

Рис. 4. Биологический запас лекарственных растений в насаждениях с максимальной урожайностью, кг

размещения площадей в зависимости от типа условий местопроизрастания и типа леса. При этом можно сделать следующие выводы:

1. Заготовка лекарственных растений на территории лесхоза возможна по всем рассматриваемым видам лекарственных растений в соответствии с лесохозяйственным регламентом Лисинского УОЛХ.

2. Информация о запасах и размещению лекарственных растений позволит оптимизировать работы по выбору маршрутов заготовки приоритетных видов сырья.

3. С помощью ГИС-технологий был определен биологический запас рассматриваемых видов лекарственных растений.

4. Пространственный анализ позволил определить районы с максимальной урожайностью лекарственных растений.

5. Географические информационные системы могут применяться в качестве инструмента для мониторинга, инвентаризации, охраны и организации промышленной заготовки лекарственного сырья.

6. Разработанные технологии могут быть использованы для определения урожайности грибов и дикорастущих ягод.

\section{Библиографический список}

1. Alekseev, A. S. Effects of Topography on the Structure and Productivity of Forest Landscapes Using 3D Modeling in Terms of the Lisinsky Educational and Experimental Forest Enterprise [Text] / A. S. Alekseev, A. A. Nikiforov // Contemporary Problems of Ecology. - Springer, 2014. - № 7. - P. 815-826.

2. Grebner, D. L. Introduction to Forestry and Natural Resources [Text] / D. L. Grebner, P. Bettinger, J. P. Siry. Academic Press, 2013. - 508 p.

3. Maplnfo Professional [Text] : User Guide. - New York : Pitney Bowes Software Inc., 2014. -540 p.

4. Qayum, A. Traditional Knowledge System Based GIS Mapping of Antimalarial Plants: Spatial Distribution Analysis [Text] / A. Qayum, A. Lynn, R. Arya // Journal of Geographic Information System. - 2014. - № 6. - P. 478-491.

5. Герасимов, Ю. Ю. Геоинформационные системы [Текст] / Ю. Ю. Герасимов, С. А. Кильпеляйнен, Г. А. Давыдков. - Йоэнсуу, 2001. - 201 с.

6. Инструкция о порядке создания и размножения лесных карт [Текст] / Государственный комитет СССР по лесному хозяйству. - M, 1987. - 80 с.

7. Руководство по учету и оценке второстепенных лесных ресурсов и продуктов побочного лесопользования [Текст] / Л. Е. Курлович [и др.]. - М., 2003. - 316 с.

8. Лесное ресурсоведение [Текст] : учеб. пособие / А. И. Жукова [и др.]. - СПб., 2008. - 206 с.

9. Лесохозяйственный регламент учебно-опытного лесничества Ленинградской области [Текст]. - СПб., 2013. -255 c.

10. Никифоров, А. А. Разработка информационной системы Лисинского УОЛХ с применением ГИС-технологий [Текст] / А. А. Никифоров // Сб. докл. молодых ученых на ежегодной науч. конф. Санкт-Петербургской лесотехнической академии. - СПб., 2002. - № 6. - С. 54-59.

11. Никифоров, А. А. Анализ распределения дикорастущих ягодников по типам леса на территории Лисинского УОЛХ с применением ГИС-технологий [Текст] / А. А. Никифоров, А. И. Жукова // Известия Санкт-Петербургской лесотехнической академии. - 2010. - № 191. - С. 4-13. 


\section{Природопользование}

12. Лисино. 200 лет служения лесам России [Текст] : моногр. / А. В. Селиховкин [и др.]. - СПб, 2009. - 224 с.

13. Цветков, В. Я. Геоинформационные системы и технологии [Текст] / В. Я. Цветков - М. : Финансы и статистика, 1998. $-288 \mathrm{c}$.

\section{References}

1. Alekseev A. S., NikiforovA. A. Effects of Topography on the Structure and Productivity of Forest Landscapes Using 3D Modeling in Terms of the Lisinsky Educational and Experimental Forest Enterprise.Contemporary Problems of Ecology. Springer, 2014, no. 7, pp. 815-826.

2. GrebnerD. L., BettingerP., SiryJ. P.Introduction to Forestry and Natural Resources. Academic PressPubl., 2013, 508 p.

3. Maplnfo Professional.User Guide. New York: Pitney Bowes Software Inc.Publ., 2014, 540 p.

4. Qayum, A., LynnA., AryaR. Traditional Knowledge System Based GIS Mapping of Antimalarial Plants: Spatial Distribution Analysis. Journal of Geographic Information System, 2014, no. 6, pp. 478-491.

5. Gerasimov Ju. Ju., Kil'peljajnenS. A., DavydkovG. A. Geoinformacionnye sistemy [Geographic Information systems]. Joensuu, 2001, 201 p. (in Russian).

6. Instrukcija o porjadkesozdanijairazmnozhenijalesnyh kart [Instruction on the order of creation and reproduction of forest maps]. Moscow, 1987, 80 p. (in Russian).

7. Kurlovich L. E.,eds.Rukovodstvo po uchetu I ocenke vtorostepennyh lesny resursov I produktov pobochnogo lesopol'zovani$j a$ [Guidelines for accounting and evaluation of secondary forest resources and forest by-products]. Moscow, 2003, 316 p. (in Russian).

8. ZhukovaA. I.,eds. Lesnoeresursovedenie [Forest resources]. Saint-Petersburg, 2008, 206 p. (in Russian).

9. Lesohozjajstvennyjreglamentuchebno-opytnogolesnichestvaLeningradskojoblasti [Forest management regulations of teaching and experimental forestry Leningrad region]. Saint-Petersburg, 2013, 255 p. (in Russian).

10. Nikiforov A. A. Razrabotka informacionnoj sistemy Lisinskogo UOLH s primeneniem GIS-tehnologij [Development of information system LisinoFES using GIS-technology]. Sbornikdokladovmolodyhuchenyhnaezhegodnojnauchnojkonferencii Sankt-Peterburgskojlesotehnicheskojakademii [Collection of reports of young scientists at the annual scientific conference of the Saint-Petersburg Forestry Academy]. Saint-Petersburg.: SPbFTAPubl., 2002, no. 6, pp. 54-59. (in Russian).

11. Nikiforov A. A.,ZhukovaA. I. Analiz raspredelenija dikorastushhih jagodnikov po tipam lesa na territorii Lisinskogo UOLH s primeneniem GIS-tehnologij [Analysis of distribution of wild berries on the forest types in the territory LisinoFES using GIS-technology].Izvestija Sankt-Peterburgskojlesotehnicheskojakademii [Proceedings of the Saint-Petersburg Forestry Academy], 2010, № 191, pp. 4-13. (in Russian).

12. Selihovkin A. V.,eds. Lisino. 200 let sluzhenijalesamRossii [Lisino. 200 years of service to the forests of Russia].Saint-Petersburg, 2009, 224 p. (in Russian).

13. Cvetkov V. Ja. Geoinformacionnye sistemy I tehnologii [Geographic Information Systems and Technologies]. Moscow: FinansyistatistikaPubl., 1998. - 288 p. (in Russian).

\section{Сведения об авторах}

Никифоров Александр Александрович - доцент кафедры лесной таксации, лесоустройства и ГИС ФГБОУ ВО «Санкт-Петербургский государственный лесотехнический университет имени С.М. Кирова», кандидат сельскохозяйственных наук, доцент, г. Санкт-Петербург, Российская Федерация; e-mail: alex_nikiforov@mail.ru.

Никифорова Антонина Ивановна - доцент кафедры технологии лесозаготовительных производств ФГБОУ ВО «Санкт-Петербургский государственный лесотехнический университет имени С.М. Кирова», кандидат технических наук, доцент, г. Санкт-Петербург, Российская Федерация; e-mail: zhukova_tonya@mail.ru.

\section{Information about authors}

Nikiforov Alexander Alexandrovich - Associate Professor of the Department of Forest Inventory, Management and GIS, Federal State Budget Education Institution of Higher Education «Saint-Petersburg State Forest Technical University named after S.M. Kirov», Ph.D. in Agriculture, Associate Professor, Saint-Petersburg, Russian Federation; e-mail: alex_nikiforov@mail.ru

Nikiforova Antonina Ivanovna - Associate Professor of the Department of Technology of Logging Industries, Federal State Budget Education Institution of Higher Education «Saint-Petersburg State Forest Technical University named after S.M. Kirov», Ph.D. in Engineering, Associate Professor, Saint-Petersburg, Russian Federation; e-mail: zhukova_tonya@mail.ru 